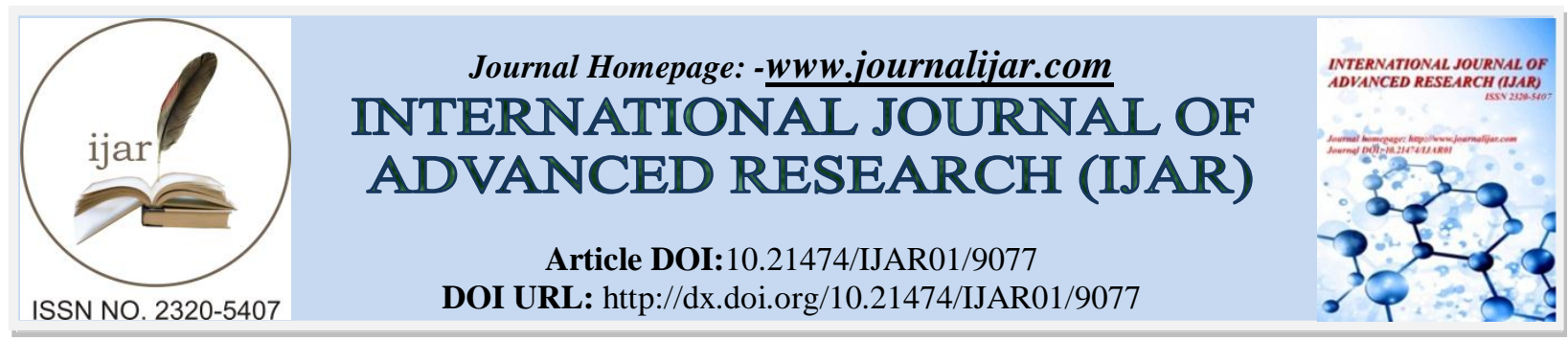

RESEARCH ARTICLE

\title{
EXPERIENCES SHARING THROUGH THE INTERVIEWS FROM TWENTY ONE PARENTS OF CHILDREN WITH CEREBRAL PALSY IN GUJARAT REGION OF INDIA.
}

Dr. Vivek H. Ramanandi (PT) ${ }^{1}$, Dr. Dhara Panchal (PT) ${ }^{2}$ and Dr. M. M. Prabhakar (MS) ${ }^{3}$.

1. MPT (Neuro), Ph.D. Scholar, Senior Lecturer, Satish Goswami College of Physiotherapy, Ahmedabad.

2. MPT (Ortho), Senior Lecturer, Pioneer Physiotherapy College, Vadodara.

3. MS (Ortho), Superintendent, Civil Hospital, Ahmedabad.

\section{Manuscript Info}

\section{Manuscript History}

Received: 15 March 2019

Final Accepted: 17 April 2019

Published: May 2019

Key words:-

Cerebral Palsy, Parents, Difficulties,

Family Centered Care, Physiotherapy, India.

\begin{abstract}
Background and Objective: Caring for a child with a disability presents a multifaceted challenge for managing and coping with the child's functional limitations and possible long term dependence to the caregiver and family. A wide range of difficulties are experienced by the parents of children with $\mathrm{CP}$.

Methods: The study utilized an interview format to examine the difficulties experienced by mothers of children with cerebral palsy. Interviews were conducted in the Gujarat region of India between June 2016 and December 2016, from various physiotherapy and rehabilitation centres with the mothers of 21 children with cerebral palsy. Face to face interviews were held in a suitable physical environment using a semi-structured questionnaire without the use of a recorder.

Results: The parents are found to be troubled with many difficulties including problems with personal relations, social and economic problems, issues involving the sick child's care and education, worries about future of the child, need for more support services etc.

Conclusion: In the light of these findings, we recommend that physiotherapy and rehabilitation centres catering to the children with cerebral palsy should focus to provide a professional approach to reviewing the difficulties parents face and emphasize the importance of family's role in rehabilitation.
\end{abstract}

Copy Right, IJAR, 2019,. All rights reserved.

\section{Introduction:-}

Family is considered to be the basic unit of sociological foundation of Indian society. In the general sense, children are considered as the common product of a male and female, which is responsible of continuing of the generations, the connection between a husband and wife, their parents' expected insurance for the future, the gift given by a mother and the symbol of love ${ }^{[1,2]}$. However, when children come into the world physically challenged, the expectations will change. In such a situation, the happiness and joy, which should accompany child's birth, is replaced by sadness and complex psychological dilemma ${ }^{[3]}$.

Many families with children that have cerebral palsy (CP) carry the anxiety and distress of adaptation related with lack of knowledge about what they can do for their child or the impact the child will have on their own lives ${ }^{[4,5]}$. 
Usually, the mother is the primary caregiver in such case and it is common that the mother will be under great psychosocial stress. For this reason, the mothers of children with cerebral palsy have higher prevalence of depression, high stress levels, and a significant relationship between their quality of life and the type and amount of disability of their child's cerebral palsy ${ }^{[5,6,7]}$. Because of the parents' important role in supporting and caring of the afflicted children, the amount of difficulties being faced by them should be studied in extensive and exploratory manner. It has been reported in previous studies on parents of children with cerebral palsy, that parents experience anxiety, depression, guilt and low self-esteem, frustration, low matrimonial and personal satisfaction due to feelings of inadequacy for not being able to have a normal child, and also that they have impaired sexual lives ${ }^{[9,10,11,12,13]}$. As the studies exploring the effect of such difficulties on the Gujarati population in particular are limited in number. This study, of qualitative design, aims at exploration of the difficulties experienced by the parents and concepts related to the said difficulties.

\title{
Materials and Methods:- Study Group and Sample Size
}

Interviews were conducted at various physiotherapy and rehabilitation centers in the Gujarat region of India between June-2016 and December-2016. The Participants were selected from parents who were currently receiving services for their children at outpatient physiotherapy centers and at home in Ahmedabad and Vadodara. The inclusion criteria included parents of children aged 0-12 years who are clinically diagnosed as having cerebral palsy. The exclusion criteria were: unwillingness of the parents to participate, parents of children with other disorders, parents diagnosed with psychological and cognitive-behavioral illness, parents with long history of diagnosed medical condition or illness. In particular we conducted in-depth interviews with participants to identify said aspects in parents of children with cerebral palsy.

\section{Collection of Data}

The eligible parents were selected for in-depth interview between June-2016 to December-2016 using purposive sampling after obtaining informed consent from them. Total 21 parents were interviewed in Gujarati using a semi structured adjustable, interview guide format developed for the study, until the data were saturated ${ }^{[13]}$. The main domains for the interview were determined by extensive literature review and were inclusive of categories related to socio-demographic, psychological, emotional and social categories. The interview format was kept adjustable to provide flexibility for use of heuristic questions such as, "Explain more." or "What do you mean exactly?" The responses were briefly noted during interview and transcribed immediately after the interview was completed. The duration of interview varied from 60-90 minutes and each parent was interviewed in 1 or 2 sessions as per need.

\begin{abstract}
Analysis
The interviews were transcribed the same day, compared with the observer's notes, with interesting points being noted, if any. The verbatim transcription of the interview was read several times (familiarization) once all the interviews were completed. The common/frequently mentioned ideas such as the respondents' view points, recurrent statements and experiences were extracted and were grouped under themes (condensation). Then the whole data were indexed or coded to categorize the concepts in the respondents while preserving the core (indexation). The data were then reconstructed based on the index at a more abstract level using reduction and induction method (abstraction) ${ }^{[14,15]}$.
\end{abstract}

\section{Results:-}

Descriptive Findings about the Families

All but two of the participants in the interviews were mothers of children with $\mathrm{CP}$, who were shouldering the responsibilities of caring for their children as Primary Caregivers.Table-1 shows the distribution of the subjects' socio-demographic characteristics.

Findings of the Interviews with the Mothers Feelings the Mothers had When They First Learned of Their Child's Diagnosis and How They Acknowledged the Existence of the Illness

Most of the parents with children with CP said that they were greatly disappointed when they first learned of the diagnosis. They said that they were shocked and were very frightened because they knew nothing about the disease. Many of them said they felt guilty for bringing such a child into the world. It was seen however that fathers had more difficulty accepting their child's sickness as compared to mothers. 
Mother 3: "When we first heard about the illness, our dreams were smashed. It took a long time for him to acknowledge my child's illness. I accepted it sooner."

Mother 5: "We learned about my child's illness when he was 3 months old. My husband and I were very upset."

\section{Difficulties Parents Face in Caring for a Child with CP}

Because children with CP are unable to walk, they have to be lifted and carried continuously leading to the mothers reporting of musculoskeletal complaints such as back pain and shoulder pain. They also complained of irregular sleep patterns, saying that they had to wake up 3-4 times in a night to check up on their child. Another complaint was that their relations with their friends and relatives

Table 1:-Socio Demographic Profile

\begin{tabular}{|c|c|c|}
\hline STUDY PARTICIPANTS & & \\
\hline No. of participants & & 21 \\
\hline Mean Age (Years) & & 35.85 \\
\hline Education & & \\
\hline & Graduate \& more & 12 \\
\hline & Upto High School & 3 \\
\hline & Upto Primary School & 4 \\
\hline & None & 2 \\
\hline Occupation & & \\
\hline & Housewives & 18 \\
\hline & Working & 3 \\
\hline Type of Family & & \\
\hline & Joint & 15 \\
\hline & Nuclear & 6 \\
\hline Mean no. of family members & & 6.17 \\
\hline Mean no. of children & & 1.86 \\
\hline Economic status & & \\
\hline & Good & 8 \\
\hline & Average & 12 \\
\hline & Poor & 1 \\
\hline CHILDREN OF PARTICIPANTS & & \\
\hline Mean Age (Years) & & 6.57 \\
\hline Sex & & \\
\hline & Male & 14 \\
\hline & Female & 07 \\
\hline Type of Diagnosis (Topogra & & \\
\hline Spastic & Diplegic & 13 \\
\hline & Hemiplegic & 2 \\
\hline & Quadriplegic & 3 \\
\hline Athetoid & & 2 \\
\hline Dyskinetic & & 1 \\
\hline
\end{tabular}

have suffered after the birth of their child. They have to adjust and compromise their social life on account of caring for the child. Most of the mothers said that they had financial difficulties due to the care giving expenses of their children. 
Mother 6 (6 year old male child): "I have taken on the full burden of caring for the child. As I have to be with him all through the day, I can't get any rest. I have trouble giving him a bath, feeding him. Since he has a problem with swallowing, it takes me an hour-and-a-half to feed him. This is really tiring for me."

Mother 17 (4 year old female child): "Since she is unable to walk, I always have to carry her. She gets aggressive for no reason which makes my day more frustrating. We experience a lot of financial difficulty because of the physiotherapy and medical costs."'

\section{Relationships of Parents with Children with CP}

It was reported that the mothers that were the primary caregivers of the children with CP had a closer relationship with the child. Fathers were less tolerant and disinterested toward their children. It was also seen that the mother was blamed for the birth of the disabled child. The internal dynamics of family relationships suffered because of this.

Mother 1: "My husband and my mother-in-law always blamed me for the birth of a child with disability. Even after these many years, they still mention this many a times. My husband doesn't tae much interest in my child. I'm the one who takes care of all of his needs."

Mother 7: "It feels like I intentionally brought the child into the world by myself; my husband doesn't support me in any way. He yells at my child and scolds him as if he were a normal child; he can't accept his illness."

\section{Relationships between Children with $\mathrm{CP}$ and Their Siblings}

Six of the children with CP had no siblings. Twelve of the mothers reported no problem in the relationships between their children, that they got along well, and that the siblings were helpful and supportive. Three of the mothers, however, reported incidences of difficulties between the siblings, mentioning the sibling's difficulty in accepting the child with disability.

Father 9: "He doesn't allow his brother to sit peacefully when he is doing homework, he tries to take his notebook or pens and when they're not given to him, he throws a tantrum or starts crying. There are a lot of other problems between the siblings."

Mother 12: "His older brother is not able to accept him; he doesn't want to take him along while going somewhere."

\section{Availability of Social Support for Parents}

Most of the parents stated that the close relatives provide major support while some said that they are not getting any support from anybody.

Mother 2: "Our relatives are all living their own lives. We can’t get any support from anybody. They never ask us if we need anything. We have to manage everything by ourselves."

Mother 19: "We have some relatives living nearby but they don't ask us if we need any support. I think they believe that it will become a routine for them if they once helped us by taking responsibility of our child even for a short duration."

\section{Worries of Parents about the Future}

All the mothers were worried about what would happen to their children when they died, who would look after them.

Mother 11: "Who's going to look after my child if something happens to me? I don't know how much his sibling or his father can look after him. It is impossible for them to care for him like I do."

Mother 21: "My son is 3 years old and he is not able to talk. I want him to have enough of abilities so that he can care for himself. I pray every night that God please make him at least independent so he can live without us."

\section{Expectations of Parents for the Future}

Parents stated that they wish for good health for both themselves as well as for their children and express their hope that their children can at least be so much independent that they can take care of themselves. 
Mother 5: "I don't have high expectations such as his becoming a doctor or an engineer. But I want him to be on his own. I'm praying to God."

Father 9: "I wish for good health for my child. But as parents, we have to stay healthy and active so that we can care for him and provide him better opportunities."

\section{Educational Difficulties Experienced by Parents}

Almost all of the parents stated that they were unable to find a suitable institution to place the child. They felt that the teachers at school were inadequate in terms of the child's education and that they may not pay them the attention they needed.

Mother 4: "They must build a school for them. I have been looking for a special school where we can keep our children every day and have people who can look after them but I can't find one."

Mother 7: "He hasn't started going to school. But I believe that he's going to have trouble when he starts. I want my child to have a good education, to be able to stand on his own."

\section{Discussion:-}

Feelings the Mothers had When They First Learned of Their Child's Diagnosis and How They Acknowledged the Existence of the Illness

Parents who have a child with a disability have a difficulty in acknowledging the existence of the it and coping with it. All of the parents said that they were shocked when they first came to know about the diagnosis, that they were very disappointed, were very frightened as they knew nothing about the disease, and also felt responsible \& guilty for giving birth to such a child. Other studies in the field also demonstrate that the first and the commonest reaction of parents to knowing that their child is disabled is shock ${ }^{[16,17,18]}$.

\section{Difficulties Parents Face When Caring for a Child with CP}

As children with CP are unable to walk and take care of themselves, they have to be lifted and carried continuously which leads to the mothers having musculoskeletal problems such as back pain and shoulder pain. They also complained of irregular sleep patterns, saying that they had to wake up 3-4 times in a night to check up on their child. They had to sleep alongside their child because the child had the risk of a seizure during the night. Another complaint was that their relations with their friends suffered after the birth of their sick child. All of the mothers said that they had financial difficulties related to the care they gave their children.

Children with disability need to learn to be independent, to be able to take control of them like their healthy counterparts ${ }^{[19]}$. When a family is unable to accept a child's disability and continue protective attitude toward the child, it prevents a child with CP from learning to lead an independent life. Rehabilitation centers established for this purpose serve to improve muscle strength, prevent postural problems, and ensuring that children with $\mathrm{CP}$ can learn to function independently or with the least amount of dependency.

As reported in the available literature, the families with children with cerebral palsy have to cope with many difficulties including relations with family members, relatives, neighbors, and others; an adverse effect on marital relationship; various psychological problems, such as sleep disturbances, emotional problems as a result of stress from caring for the child; increased likelihood for numerous physical health problems; negative effect on mother's employment status, financial pressure on parents, and insufficient support services etc ${ }^{[5,6,7,9,10,11,12,13]}$. At the same time, the parents of children with disability feel the need for support and assistance to meet the needs of their child in their daily care. It has been reported that parents who are supported by people around them feel less lonely and are better in their ability to cope with their problems ${ }^{[5,9,12,13]}$.

\section{Relationships of Parents with Children with CP}

Mothers are considered the primary caregivers for the children with $\mathrm{CP}$, as they are very close to their children, whereas fathers are less interested and had less tolerance toward their children. It was observed that the mother was blamed for the birth of the child with disability and that family relationships were affected due to this. Studies in the past have shown that living with a disabled child creates social, psychological and economic problems for parents ${ }^{[4,}$ 9]. Acceptance of a child with disability is a very difficult process for all the family members. Individual support programs for members will help the child as well as other members adapt more easily to live within the family. 
There are no such support programs in India however. Since women are in the primary role of caregiver, especially in India, it is inevitable that mothers are the ones to experience the most problems. In family situations where caregiving is assumed to be what is expected of the mother, the tasks are not divided evenly between husband and wife couples are more likely to experience friction ${ }^{[6]}$.

\section{Relationships between Children with $\mathrm{CP}$ and Their Siblings}

Parents reported incidences of sibling's difficulty in accepting the child with disability. In families with children with $\mathrm{CP}$, where there are more siblings, the time which may be allotted to the sick child's care may be less or, on the other hand, due to increased time demands of caring for the sick child the other siblings may be getting lesser attention ${ }^{[20,21]}$. A child with disability may impair the rituals of family life as well as marital relations between the couple. It will be the other children in the family that will be most likely to be affected by this. The same situation may also lead to a number of negativities and changes in the relationships between family members, making a normal family life difficult ${ }^{[22]}$.

\section{Availability of Social Support for Parents}

In general terms, social support can be defined as the material and moral help provided to an individual by the people surrounding him/her (spouse, family, friends) ${ }^{[23]}$. Two different studies, conducted on children with CP and autism, have concluded that the anxiety levels of women receiving good social support were found to be low ${ }^{[24,25]}$. It has been found that parents who share their responsibilities with others and are supported by the people around them feel less alone and that because of this, they can better cope with the problems that they face ${ }^{[6,7,13]}$. Many studies however point to emotional or interpersonal negativities between couples in families where there is a child with disability ${ }^{[19,26]}$.

\section{Worries of Parents about the Future}

One common concern experienced by all of the participants stressed on the future of the child. Their biggest worry was what would happen to their children when they died, who would look after them. A similar finding was observed in the study by Heaman, in which the most common stressor reported by mothers and fathers was a concern about the child's future ${ }^{[27]}$.

The biggest worries of the parents about the future included the uncertainties about what would await the children with disability in the future and how they would survive when their parents got old or died. Similar results were obtained in other studies conducted in past as well ${ }^{[9,13,22,27,28]}$.

\section{Expectations of Parents for the Future}

The parents in this study stated that they wish for good health for both themselves as well as for their children and express their hope that their children can at least be so much independent that they can take care of themselves. Many studies on children with disability indicate that parents wish most that their children can come to a point where they can live on their own ${ }^{[1,4,7]}$.

\section{Educational Difficulties Experienced by Parents}

In our study, almost all of the parents stated that they were unable to find a suitable institution to place the child. They felt that the teachers at school were inadequate in terms of the child's education and that they may not pay them the attention they needed. It is also supported by various studies in the field that in the case of a child with disability, special care requirements, treatment and educational problems, as well as the extra burden of increasing financial needs and the decreased time spent on the other children in the family impose hardships on normal family life $^{[12,13,28]}$.

\section{Findings and Suggestions}

The results of this study suggest that parents who have children with $\mathrm{CP}$ are faced with many difficulties including but not limited to the personal relations, social problems, economic problems, personal physical problems, issues involving the sick child's care and education. It was observed that the major responsibility regarding the child's care was primarily on the mothers. Other common difficulties such as worries about future of the child, need of better support services, and lack of adequate number of training centers were experienced by the parents. In the light of these findings, our recommendation is that physiotherapy and rehabilitation centers catering to the needs of children with $\mathrm{CP}$ should focus on reviewing the difficulties parents face and provide education to them so they can better cope with the condition, resulting in improved outcomes associated with treatment. 


\section{Acknowledgements}

The authors would like to acknowledge the support and enthusiasm of all the subjects who participated. Special gratefulness is extended to all the authors, writers and editors of the books, journals and web content which have provided us with motivation and guidance in conducting research in such an important issue.

\section{Conflict of Interest}

No potential conflict of interest.

\section{Source of Funding}

No funding received.

\section{Ethical Clearance}

Taken from Institutional Ethics Committee of Satish Goswami College of Physiotherapy vide SGCP/IEC/2018/004 dated, $07^{\text {th }}$ September, 2018.

\section{References:-}

1. Ataman A. Reasons for Being in Need of Special Education. Daytime Education Publishing, Ankara. 2003.

2. Ozguven IE. Marriage and Family Therapy. PDREM Publications, Ankara. 2000.

3. Akkok F. Families with Children with Different Feature and Family Studies. Gunduz Education, Ankara. 2003.

4. Davis E, Waters E. Children with cerebral palsy, psychometric analysis and quality of life. In: Preddy VR, Watson RR (editor) Handbook of Disease Burdens and Quality of Life Measures. Springer, New York. 2010: pp. 3657-3670.

5. Ramanandi VH, Rao B. Comparison of Stress Levels in The Parents of Children with Cerebral Palsy and Parents of Normal Children in Vadodara Region of Gujarat. Int J Physiother. 2015; 2(2): 421-428.

6. Davis E, Shelly A, Waters E, Boyd R, Cook K, Davern M. The impact of caring for a child with cerebral palsy: quality of life for mothers and fathers. Child: care, health and development. 2010; 36(1): 63-73.

7. Brehaut JC, Kohen DE, Raina P, Walter SD, Russell DJ, Swinton M. et al. The health of primary caregivers of children with cerebral palsy: how does it compare with that of other Canadian caregivers? Pediatrics. 2004; 114(2): e182-e191.

8. Hutton JL, Pharoah POD. Life expectancy in severe cerebral palsy. Arch Dis Child. 2006; 91(3): 254-258.

9. Raina P, O'Donnell M, Rosenbaum P, Brehaut J, Walter SD, Russell D, et al. The health and well-being of caregivers of children with cerebral palsy. Pediatrics. 2005;115(6):e626-e36.

10. Majnemer A, Shevell M, Law M, Poulin C, Rosenbaum P. Indicators of distress in families of children with cerebral palsy. Disabil Rehabil. 2012;34(14):1202-7.

11. Diwan S, Chovatiya H, Diwan J. Depression and quality of life in mothers of children with cerebral palsy. NJIRM. 2011; 35: 81-90.

12. Nimbalkar S, Raithatha S, Shah R, Panchal DA. A qualitative study of psychosocial problems among parents of children with cerebral palsy attending two tertiary care hospitals in western India. ISRN family medicine . 2014, Article ID 769619, 6 pages.

13. Ramanandi VH, Jayswal MD, Panchal DN. A qualitative study to conceptualize levels of awareness, acceptance and expectations in parents of children with cerebral palsy in Gujarat, India. Int J Contemp Pediatr. 2018; 5: 442-447.

14. Graneheim UH, Lundman B. Qualitative content analysis in nursing research: concepts, procedures and measures to achieve trustworthiness. Nurse education today. 2004; 24(2): 105-112.

15. Burnard P. A method of analysing interview transcripts in qualitative research. Nurse education today. 1991; 11(6): 461-466.

16. Pelchat D, Lefebrune H, Perault M. Differences and similarities between mother and fathers' experiences of parenting a child with disability. J Child Care. 2003;7(4): 231-247.

17. Ferguson PM. A place in the family: an historical interpretation of reactions to having a child with a disability. $\mathbf{J}$ Special Educ. 2002; 36: 124-136.

18. Baird G, McConachie H,Scrutton D.Parents' perceptions of disclosure of the diagnosis of cerebral palsy. Arch Dis Child. 2000; 83: 475-480.

19. Hall HR, Neely-Barnes SL, Graff JC, Krcek TE, Roberts RJ, Hankins JS. Parental stress in families of children with a genetic disorder/disability and the resiliency model of family stress, adjustment, and adaptation. Issues in comprehensive pediatric nursing. 2012; 35(1): 24-44. 
20. Girli, A., Yurdakul, A., Sarısoy, M., Ozekes, M.: Group counseling for parents of autistic children withmental disabilities and depression, self-esteem and its effect on attitudes. Saray Rehabil. 6, 2-9 (2000)

21. Yavuz B, Cimen S. Investigation of the fulfilment levels of the self-care skills of the children with cerebral palsy and affectional factors. Cumhuriyet Journal of Nursing. 2007; 11(1):17-26.

22. Gray DV. High functioning autistic children and the construction of "normal family life". Soc Sci Med. 1997; 44(8): 1097-1106.

23. Cakır Y, Palabıyıkoglu R. Reliability and validity study of multidimensional scale of perceived social support. J Crisis. 1997; 5(1): 15-24.

24. Coskun Y, Akkas G. Trait anxiety levels of mothers with disabled children with the relationship between social support perceptions. J Educ Ahi Ervan Univ. 2009; 10(1): 213-227.

25. Sencar B. Research of Interrelationships Between Social Support and Stress Level that the Families of Autistic Child Perceived. Master thesis, Dokuz Eylul University, Institute of Education Sciences, Izmir. 2007.

26. Mendenhall A, Mount K. Parents of children with mental illness: Exploring the caregiver experience and caregiver-focused interventions. Families in society: The Journal of Contemporary Social Services. 2011; 92(2):183-90.

27. Heaman DJ. Perceived stressors and coping strategies of parents who have children with developmental disabilities: a comparison of mothers with fathers. Journal of pediatric nursing. 1995; 10(5): 311-320.

28. McConkey R, Kennedy MT, Chang MY, Jarrah S, Shukri R. The impact on mothers of bringing up a child with intellectual disabilities: a cross-cultural study. Int J Nurs Stud. 2008; 45: 65-74. 